\title{
Produtividade Agrícola e Segurança Alimentar dos Domicílios das Regiões Metropolitanas Brasileiras
}

\author{
Lorena Vieira Costa ${ }^{1}$, Marília Fernandes Maciel Gomes ${ }^{2}$, \\ Viviani Silva Lírio ${ }^{3}$ e Marcelo José Braga $^{4}$
}

\begin{abstract}
Resumo: $\mathrm{O}$ crescimento agrícola pode afetar o nível de bem-estar de uma população mediante a possibilidade de elevação da oferta de alimentos, com reflexo em menores preços e na qualidade da dieta das pessoas. Assim, buscou-se, neste trabalho, verificar a relação entre a produtividade agrícola brasileira dos principais itens constituintes da dieta da população e a segurança alimentar dos domicílios das regiões metropolitanas brasileiras. Utilizou-se um modelo de escolha qualitativa, o probit, e dados das Pesquisas de Orçamentos Familiares (POF) de 1995-1996, 2002-2003 e 2008-2009 e da pesquisa de Produção Agrícola Municipal (PAM). Foram verificadas importantes relações entre a escolaridade do chefe do domicílio, a presença de pessoas menores de 18 anos na família e o fato de o domicílio obter renda per capita inferior a um salário mínimo e a segurança alimentar. Além disso, o crescimento da produtividade dos grãos, das verduras e legumes e das frutas associou-se à maior probabilidade de segurança alimentar em pelo menos um dos períodos analisados. Conclui-se que os ganhos de produtividade associam-se à maior segurança alimentar domiciliar, porém, em baixas proporções, devido à alta influência de fatores particulares aos domicílios, como escolaridade e renda.
\end{abstract}

Palavras-chaves: Segurança alimentar, gasto com alimentação, produtividade agrícola.

Abstract: One of the principal means by which agricultural growth affects the level of welfare of the population is the possibility of increasing the food supply, which generally reflects in lower food prices, with important implications on people's diet. Thus, this study

1 Doutoranda em Economia Aplicada pela Universidade Federal de Viçosa (UFV). E-mail: lorenavieiraufv@yahoo.com.br

2 Professora Associada do Departamento de Economia Rural da Universidade Federal de Viçosa. E-mail: mfmgomes@ufv.br

3 Professora Associada do Departamento de Economia Rural da Universidade Federal de Viçosa. E-mail: vslirio@yahoo.com.br

4 Professor Associado do Departamento de Economia Rural da Universidade Federal de Viçosa. E-mail: mjbraga@ufv.br 
aimed to investigate the relationship between the agricultural productivity of the main items of people's diet and food security of households in metropolitan regions. We used a qualitative choice model, the probit, and data from the Household Budget Surveys (POF, in Portuguese) of 1995-1996, 2002-2003 and 2008-2009 and research Municipal Agricultural Production. There were significant relationships between the level of education of the household head, the presence of persons under 18 years-old in the family and the fact that the per capita income household earning is less than minimum wage and food security. Moreover, the productivity growth of grains, vegetables and fruits was associated with greater likelihood of food security in at least one of the periods analyzed. We conclude that productivity gains are associated with greater household food security, but in low proportions, due to the high influence of particular characteristics, such as education and income.

Key-words: Food security, food expenditures, agricultural productivity.

Classificação JEL: I00, O30, Q18.

\section{Introdução}

O crescimento agrícola relaciona-se diretamente com o padrão de consumo da população por meio de sua influência sobre os preços de alimentos. À medida que os alimentos se tornam mais baratos em relação a outros bens e serviços, o orçamento doméstico é realocado, com maior consumo de alimentos e menor participação desses itens na renda total domiciliar (SOUTHGATE, GRAHAM e TWEETEN, 2011). Particularmente nos países em desenvolvimento, o aumento no consumo de itens alimentícios constitui certamente uma melhoria nos padrões de bem-estar e, para alguns segmentos da população, na possibilidade de atingir um nível mínimo de consumo de calorias e nutrientes essenciais à vida (GARCIA, 1979).

Assim, os ganhos de produtividade agrícola constituem uma das formas de aumento da disponibilidade de alimentos e redução dos preços, o que contribui para a garantia de segurança alimentar da população. Conforme Babu e Sanyal (2009), atingir a segurança alimentar em nível macro requer um crescimento econômico que resulte em redução de pobreza e de desigualdades na distribuição de renda entre a população. Em uma economia agrária, o crescimento econômico é impulsionado pelos ganhos na produtividade agrícola e, assim, dependem de recursos como os naturais, humanos e de tecnologia agrícola.

Conforme Contini et al. (2010), o aumento da produção agropecuária no Brasil nas últimas décadas indica uma resposta positiva da produção diante do aumento da população, representando, assim, um bom indicador no contexto da preocupação com a segurança alimentar. Os autores verificaram crescimento de $3,66 \%$ ao ano na produção brasileira de arroz, milho, feijão, soja e trigo entre 1975 e 2010 . Com a modernização agrícola brasileira, cujo estímulo inicial deu-se em meados da década de 1960, foi possível alcançar forte industrialização do campo, com resultado no aumento significativo da produtividade da terra, do trabalho e do capital, principalmente nos últimos 30 anos (CONTINI et al., 2010). De acordo com Gasques et al. (2010), a taxa de crescimento da produtividade total dos fatores da agropecuária brasileira entre 1975 e 2009 foi de $3,57 \%$ ao ano.

Conforme Buainain e Vieira (2009), a relação inversa entre produtividade e preços é amplamente reconhecida e é particularmente aplicável ao caso da produtividade da terra e dos preços agrícolas. Segundo Mendonça de Barros, Rizzieri e Picchetti (2001), para cada 1\% de elevação da produtividade da área há uma correspondente queda de aproximadamente $2 \%$ nos preços reais 
do arroz, feijão, açúcar, óleo de soja, cebola e laranja $(-2,1 \%,-2,47 \%,-2,54 \%,-2,46 \%,-2,07 \%$ e $-2,01 \%$, respectivamente, para o período entre 1975 e 2000).

No que se refere à prevalência de insegurança alimentar no Brasil, dados do IBGE (Instituto Brasileiro de Geografia e Estatística) indicam que $34,9 \%$ dos domicílios estavam em situação de insegurança alimentar em 2004, e 30,2\%, em 2009. No Sul, $81,3 \%$ dos domicílios estavam seguros em 2009, no Nordeste e Norte, $46,1 \%$ e 40,2\% dos domicílios enfrentavam algum tipo de insegurança alimentar, respectivamente. A incidência de insegurança alimentar moderada e grave observada na região Nordeste foi quase quatro vezes maior que a da região Sul, $21,3 \%$ contra $5,4 \%$ (IBGE, 2010) ${ }^{5}$.

Conforme o Índice Global de Segurança Alimentar, elaborado pela Economist Intelligence Unit (2012), o Brasil encontra-se em 310 lugar no ranking de segurança alimentar, entre 105 países. Esse índice considera três pilares principais para a avaliação: a acessibilidade financeira que oferece condições para a aquisição de alimentos, a disponibilidade e a qualidade dos alimentos disponíveis. $\mathrm{O}$ gasto com alimentos proporcional à renda de uma família é uma das medidas utilizadas para avaliar a acessibilidade domiciliar aos alimentos. Além disso, como determinante da disponibilidade alimentar estão os gastos públicos em pesquisa e desenvolvimento para a agricultura, que oferecem uma indicação do grau tecnológico e de inovação na produção agrícola.

Face ao exposto, busca-se neste trabalho, analisar a relação entre o crescimento agrícola, tendo como fonte os ganhos de produtividade, e os níveis de segurança alimentar da população brasileira, com o objetivo de contribuir para o debate acerca da relação entre crescimento agrícola e bem-estar populacional. A segurança alimentar,

5 Conforme a Escala Brasileira de Insegurança Alimentar (Ebia), que classifica a situação de segurança alimentar em quatro graus: segurança alimentar, insegurança alimentar leve, insegurança alimentar moderada e insegurança alimentar grave. Para mais detalhes, ver Segurança Alimentar 2004, IBGE (2006). neste trabalho, é entendida como a vulnerabilidade da família em relação à satisfação de suas necessidades alimentares. Assim, estão seguros os domicílios que não comprometem grande parcela de sua renda com os gastos alimentares. Destaca-se que o principal caminho pelo qual os ganhos de produtividade atuam sobre o consumo de alimentos é por meio do seu efeito sobre os preços, afetando os gastos das famílias com os mesmos. Assim, a concepção da segurança alimentar baseada nos gastos alimentares se faz particularmente adequada aos objetivos deste trabalho.

A abordagem procedida por este trabalho foca em uma das dimensões da segurança alimentar, que é a disponibilidade de alimentos, que, por sua vez, é condicionada tanto pela oferta quanto pelos preços de alimentos. Embora se reconheça que uma maior oferta de alimentos pode ser fruto do crescimento agrícola extensivo, no qual se observa uma elevação da área plantada ou maior incorporação de mão de obra, neste trabalho analisa-se apenas o crescimento agrícola ocorrido por meio dos ganhos de produtividade, uma vez que esses foram a principal fonte de crescimento agrícola no Brasil nos últimos anos.

\section{Segurança alimentar e produtividade agrícola}

Embora a produtividade agrícola tenha sido definida de diferentes formas na literatura, os estudos concordam com a constatação de que os ganhos de produtividade são importantes para a redução de pobreza. Fan, Hazell e Thorat (1999) verificaram que os ganhos na produtividade total de fatores reduziram a pobreza rural na Índia, tanto diretamente, por meio de aumentos na renda, quanto indiretamente, mediante melhores salários e preços mais baixos de alimentos. Já Minten e Barret (2005), analisando a relação entre desempenho agrícola e pobreza rural em Madagascar, concluíram que a elevação da produtividade da terra beneficia principalmente os produtores rurais compradores líquidos e trabalhadores, por meio da redução dos preços de ali- 
mentos e pela elevação dos salários reais agrícolas de trabalhadores não qualificados. Conforme os autores, maiores níveis de rendimento agrícola estão relacionados a maiores níveis de bem-estar, medido pela situação de segurança alimentar.

De acordo com Pinstrup-Andersen e Hazell (1985), os gastos com alimentos correspondem a uma grande parcela do total de dispêndio da população pobre, de modo que o declínio dos preços dos alimentos beneficiaria essa população em maiores proporções.

No Brasil, dados da Pesquisa de Orçamento Familiares (POF) de 2008-2009 do IBGE mostram que $16,1 \%$ das despesas totais da população brasileira eram referentes à despesa com alimentação em 2009. Segundo Carvalho e Silva (2010), são as famílias de menores rendas que, em geral, despendem proporcionalmente mais recursos com alimentação: mais de $20 \%$ das famílias brasileiras vivem com renda de até dois salários mínimos ( R\$ 830,00 em janeiro de 2009) e seus gastos com alimentos perfazem $27,8 \%$ de suas despesas totais.

Segundo Maluf e Menezes (2000), o principal pressuposto da segurança alimentar refere-se à disposição de poder de compra para adquirir alimentos em quantidade e qualidade adequadas, de modo que reduza o peso relativo dos gastos com alimentação na renda familiar. Esse aspecto é condicionado por instrumentos que promovam a elevação da renda e sua distribuição equânime (emprego, salários, outras rendas e tributos), além do custo relativo dos alimentos. Esses custos, por sua vez, constituem um dos principais determinantes da renda real das famílias, particularmente daquelas dos estratos de renda inferiores. Assim, entre as iniciativas para a redução dos custos com alimentação estão o aumento da produtividade agrícola com base em técnicas social e ambientalmente adequadas, a redução do elevado nível de perdas e desperdícios, o enfrentamento de gargalos na infraestrutura de transportes e armazenamento, e a aproximação de produtores e consumidores em mercados regionais.

Diante disso, vale ressaltar o conceito brasileiro de Segurança Alimentar e Nutricional
(SAN), que é definido pela Lei Orgânica de SAN (Lei n. 11.346 de 15 de setembro de 2006):

\begin{abstract}
"A segurança alimentar e nutricional consiste na realização do direito de todos ao acesso regular e permanente a alimentos de qualidade, em quantidade suficiente, sem comprometer o acesso a outras necessidades essenciais, tendo como base práticas alimentares promotoras de saúde que respeitem a diversidade cultural e que sejam ambiental, cultural, econômica e socialmente sustentáveis" (BRASIL, 2006).
\end{abstract}

Para Kepple e Segall-Corrêa (2011), a definição brasileira constitui-se num conceito bastante abrangente, de natureza interdisciplinar e envolve questões de acesso a alimentos de qualidade, práticas alimentares saudáveis e de produção sustentável, cidadania e direitos humanos. Gubert, Benício e Santos (2010) ressaltam que o processo envolve toda a cadeia alimentar, sendo determinado por fatores que vão desde a produção agrícola, distribuição e acesso econômico aos alimentos até a própria escolha alimentar, baseada em práticas culturais.

De acordo com Sen (2010), a produção de gêneros alimentícios é uma das variáveis que pode influenciar a prevalência da fome e da insegurança alimentar, uma vez que o preço dos alimentos ao consumidor é afetado pela magnitude da produção de alimentos. No entanto, ressalta o autor, o potencial das pessoas para adquirir alimentos e obter saúde e nutrição depende não apenas da produção de alimentos e expansão agrícola, mas também do funcionamento de toda a economia e da ação das disposições políticas e sociais.

\section{Metodologia}

A produtividade agrícola foi definida como o rendimento da terra, em quilogramas produzidos por hectare plantado, das culturas selecionadas. Com base na disponibilidade de dados e ainda na relevância de cada alimento na dieta dos brasilei- 
ros, as culturas selecionadas foram: arroz, feijão, batata-doce, batata-inglesa, cebola, mandioca, milho, soja, tomate, trigo, banana, laranja, maçã e mamão. Optou-se por agregar essas culturas em quatro diferentes grupos, com o intuito de reduzir a quantidade de variáveis analisadas, além de permitir a análise da importância de cada grupo de culturas, separadamente. Essa agregação se deu da seguinte forma: as culturas do arroz e feijão foram agregadas e formaram o rendimento em quilogramas de arroz e feijão por hectare. As culturas da soja, milho e trigo foram analisadas conjuntamente, caracterizando a produtividade dos grãos. Batata-doce, batata-inglesa, cebola, mandioca e tomate constituíram a produtividade de verduras e legumes. Já a produtividade das frutas foi obtida pela agregação das culturas da banana, laranja, maçã e mamão.

A insegurança alimentar domiciliar foi avaliada com base nos dados das Pesquisas de Orçamentos Familiares (POF) do IBGE. De acordo com Smith (2002), várias medidas de insegurança alimentar podem ser construídas com base em pesquisas de orçamentos. Entre essas, tem-se o percentual de gastos com alimentos em relação à renda familiar, que trata da vulnerabilidade à privação alimentar futura, um importante componente da insegurança alimentar. Domicílios que despendem altas proporções de suas rendas com alimentação estão em situação vulnerável, uma vez que uma retração de renda compromete a satisfação alimentar dos mesmos. Essa medida também pode ser justificada pela Lei de Engel, que dispõe que, à medida que a renda familiar cresce, as despesas com alimentação diminuem percentualmente. Assim, este trabalho segue a indicação de Smith (2002), que considera inseguros aqueles domicílios com gastos com alimentação acima de $70 \%$ de sua renda.

\subsection{O uso de Pesquisas de \\ Orçamentos Familiares repetidas}

Este trabalho utiliza dados das POFs de 1995-1996; 2002-2003 e 2008-2009. A POF de 1995-1996 foi a terceira pesquisa realizada, e abrangeu as regiões metropolitanas de Belém, Fortaleza, Recife, Salvador, Belo Horizonte, Rio de Janeiro, São Paulo e Porto Alegre, além de Goiânia e Distrito Federal. As duas últimas POFs, de 2002-2003 e 2008-2009, apresentam abrangência nacional, com a inclusão da pesquisa em áreas rurais além da investigação das aquisições não monetárias.

Diante do fato de que essas pesquisas não acompanham os mesmos domicílios ao longo do tempo, têm-se três cross sections independentes. Segundo Rafferty e Walthery (2011), pesquisas desenhadas para uma nova amostra de entrevistados em sucessivos pontos do tempo constituem as cross sections independentes. Os dados podem ser analisados em um certo ano, ou as pesquisas podem ser combinadas para uma análise ao longo do tempo. Conforme Cameron e Trivedi (2005), a independência dessas amostras está no fato de que cada indivíduo, ou unidade de corte transversal, aparece em apenas uma das pesquisas.

Assim, de acordo com Wooldridge (2010), o uso do agrupamento de cross sections tem as vantagens de elevar o tamanho da amostra, oferecer estimadores mais precisos e estatísticas de testes mais poderosas. Além disso, essa agregação não leva a nenhuma correlação dos erros das observações ao longo do tempo. O autor destaca que, em geral, para refletir o fato de que a população pode ter distribuições diferentes em períodos de tempo diferentes, permite-se uma variação do intercepto ao longo dos períodos, por meio da inclusão de variáveis dummies de tempo. Dummies anuais também podem interagir com variáveis explicativas para investigar se o efeito dessa variável mudou ao longo de dado período.

\subsection{Modelos de escolha qualitativa em cross sections repetidas}

Nos modelos de escolha qualitativa, a variável a ser explicada $y$, possui resposta binária assumindo valor igual a zero ou um. Neste trabalho, $y=1$, se um domicílio está seguro quanto ao aspecto alimentar e $y=0$, caso contrário. 
De acordo com Wooldridge (2002), assim como nos modelos lineares, $y$ corresponde à variável dependente e $x \equiv\left(x_{1}, x_{2}, \ldots, x_{k}\right)$ é o vetor de variáveis explicativas. Em modelos de escolha binária, o interesse recai primariamente sobre a probabilidade de resposta, isto é:

$$
\operatorname{Pr}(y=1 \mid x)=\operatorname{Pr}\left(y=1 \mid x_{1}, x_{2}, \ldots, x_{k}\right)
$$

para vários valores de $x$.

Considerando-se modelos de escolha binária da forma:

$$
\operatorname{Pr}(y=1 \mid x)=G(x \beta) \equiv p(x)
$$

tem-se que G é uma função de distribuição cumulativa normal no modelo probit, expressa por:

$$
G(z)=\phi(z) \equiv \int_{-\infty}^{z} \phi(v) d v
$$

em que $\phi(z)$ é a densidade normal padrão:

$$
\phi(z)=(2 \pi)^{-1 / 2} \exp \left(-z^{2} / 2\right)
$$

Seja $x_{\mathrm{j}}$ uma variável contínua, então o efeito marginal de $x_{\mathrm{j}}$ na probabilidade de resposta é (WOOLDRIDGE, 2002):

$$
\frac{\partial p(x)}{\partial x_{j}}=g(x \beta) \beta_{j}, \text { em que } g(z) \equiv \frac{\partial G}{\partial z}(z)
$$

Caso $x_{\mathrm{k}}$ seja uma variável explicativa binária, o efeito marginal de se alterar $x_{\mathrm{k}}$ de zero para um, mantendo-se todas as demais variáveis constantes, é:

$$
\begin{aligned}
& G\left(\beta_{1}+\beta_{2} x_{2}+\ldots+\beta_{k-1} x_{k-1}+\beta_{k}\right)- \\
& -G\left(\beta_{1}+\beta_{2} x_{2}+\ldots+\beta_{k-1} x_{k-1}\right)
\end{aligned}
$$

Nota-se que essa expressão depende de todos os demais valores de $x_{\mathrm{j}}$.

A estimação de modelos de variáveis dependentes binárias, em razão da não linearidade de $E(y \mid x)$, deve ser feita utilizando a estimação de máxima verossimilhança ${ }^{6}$. Uma vez que essa estimação é baseada na distribuição de $\mathrm{y}$ dado $\mathrm{x}$, a heterocedasticidade em $\operatorname{Var}(y \mid x)$ é automaticamente considerada (WOOLDRIDGE, 2002).

6 Para detalhes da estimação de Máxima Verossimilhança, ver Wooldridge (2002) e Wooldridge (2010).
Embora alguns autores, como Moffitt (1993), admitirem o uso de modelagens em painel para dados em cross sections repetidas, inclusive modelos dinâmicos, este trabalho optou pela indicação de Wooldridge (2002), que trata o agrupamento como uma grande cross section. Essa opção pode ser justificada pelo fato de que os domicílios pesquisados em cada cross section não são necessariamente os mesmos, o que faz com que a inclusão dos efeitos fixos não se justifique. Assim, a estimação feita é equivalente à estimação do modelo pooled. O modelo de escolha binária utilizado refere-se ao probit, que, conforme Cameron e Trivedi (2005), oferece como atração o uso de uma variável aleatória normal latente.

As variáveis explicativas são: escolaridade do chefe do domicílio, dummy de gênero do chefe do domicílio; dummy indicativa da presença de crianças e adolescentes no domicílio e dummy que indica se o domicílio aufere renda per capita inferior a um salário mínimo. Além dessas, as demais variáveis explicativas do modelo referem-se às produtividades das culturas do arroz e do feijão, dos grãos, das verduras e legumes e das frutas. Assim como sugere Wooldrigde (2002), foram inseridas dummies de tempo ao modelo com o intuito de captar as diferenças de intercepto entre os períodos analisados, assim como interações dessas dummies com as variáveis de interesse deste trabalho, as produtividades, com o objetivo de avaliar se o efeito dessas variáveis mudou entre os anos analisados.

\subsection{Fonte dos dados e definição das variáveis}

Foram utilizados dados anuais de área plantada em hectares, bem como quantidade produzida, em toneladas, das culturas do arroz, feijão, soja, milho, trigo, batata-doce, batata-inglesa, cebola, mandioca, tomate, laranja, banana, mamão e maçã, para cada estado brasileiro, entre 1995 e 2010. Todas as informações foram provenientes da pesquisa de Produção Agrícola Municipal do IBGE (2012). As demais variáveis explicativas do modelo, já enunciadas, foram obtidas por meio das Pesquisas de Orçamentos 
Figura 1. Produtividade das culturas do feijão e arroz, em kg/ha, Brasil, 1995-2010

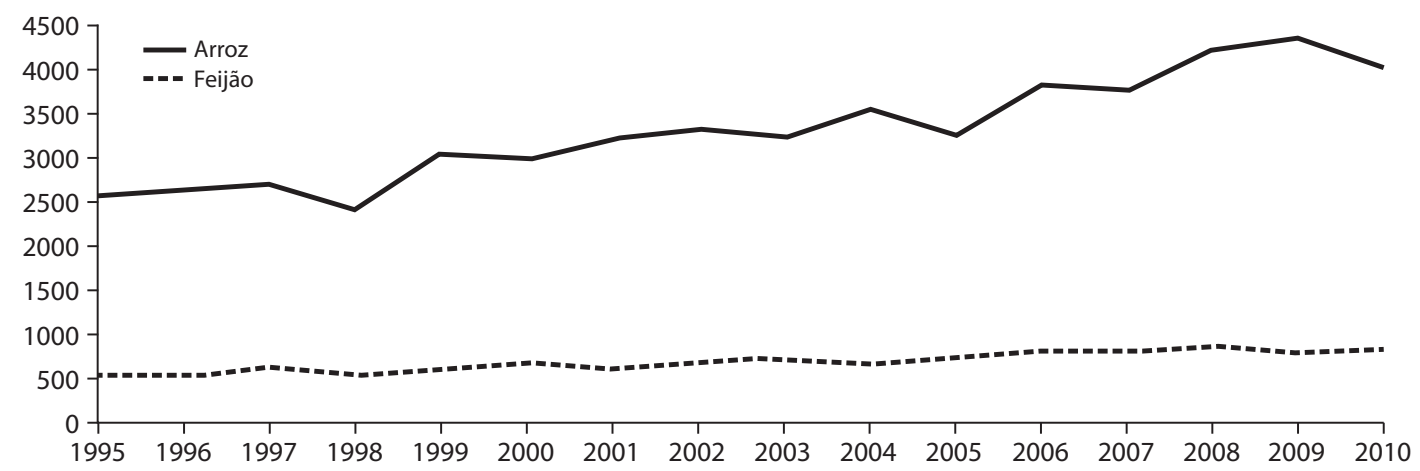

Fonte: Elaborado pelos autores a partir de dados da PAM - IBGE, 2012.

Familiares do IBGE, que também foram utilizadas para a obtenção do gasto total da família com alimentação em relação à sua renda. A renda domiciliar utilizada considera o rendimento monetário e não monetário.

Em razão de a Pesquisa de Orçamento Familiar de 1995-1996 ter envolvido apenas as nove regiões metropolitanas brasileiras, mais as capitais Goiânia e Brasília, optou-se por trabalhar com essas regiões também nas demais POFs, embora essas tenham abrangência nacional. Assim, as regiões metropolitanas analisadas foram: Belém, Fortaleza, Recife, Salvador, Belo Horizonte, Rio de Janeiro, São Paulo, Curitiba, Porto Alegre, Goiânia e Brasília. Os números de domicílios considerados pelas amostras são de 14.912 para 1995-1996; 6.108 em 2002-2003 e 7.757 em 2008-2009.

\section{Resultados e discussão}

\subsection{Os ganhos de produtividade agrícola}

A evolução do rendimento da terra na produção de arroz e feijão em todo o Brasil entre 1995 e 2010 pode ser verificada na Figura $1^{7}$. Observa-se que o crescimento da produtividade do arroz foi

7 A evolução da quantidade produzida pelo Brasil entre os anos analisados, de cada cultura selecionada, pode ser visualizada no Anexo. de 59,26\% entre esses anos. Tendência de crescimento de produtividade é também verificada para o feijão, com ganho de $57,39 \%$. Os ganhos de rendimento dessas culturas, além de importantes no contexto da segurança alimentar, também têm relevância social e econômica, visto que grande parte da produção desses itens vem da agricultura familiar (IBGE, 2009). Assim, o crescimento da produtividade observada certamente foi obtido pelos pequenos produtores. Esses ganhos, conforme destacado por Helfand e Moreira (2011), constituem um dos caminhos para a elevação na renda e redução da pobreza rural.

O crescimento da produtividade das culturas do milho, soja e trigo pode ser verificado na Figura 2. A produtividade do milho mostrou forte tendência de crescimento, com ganho de 67,05\% entre 1995 e 2010. Com tendência menos acentuada, o crescimento do rendimento da soja foi de $34,24 \%$ no período. Já a produtividade do trigo, embora tenha apresentado períodos de oscilação, obteve o maior crescimento entre os grãos: $91,02 \%$.

Alves, Contini e Hainzelin (2005) ressaltam a alta influência das exportações e do aumento do consumo de proteína animal sobre a expansão da produção de soja e milho no Brasil. Conforme Schlesinger (2008), a produção de soja orientada para a exportação resultou num intenso processo de intensificação tecnológica e elevação da produtividade. 
Figura 2. Produtividade das culturas de milho, soja e trigo, em kg/ha, Brasil, 1995-2010

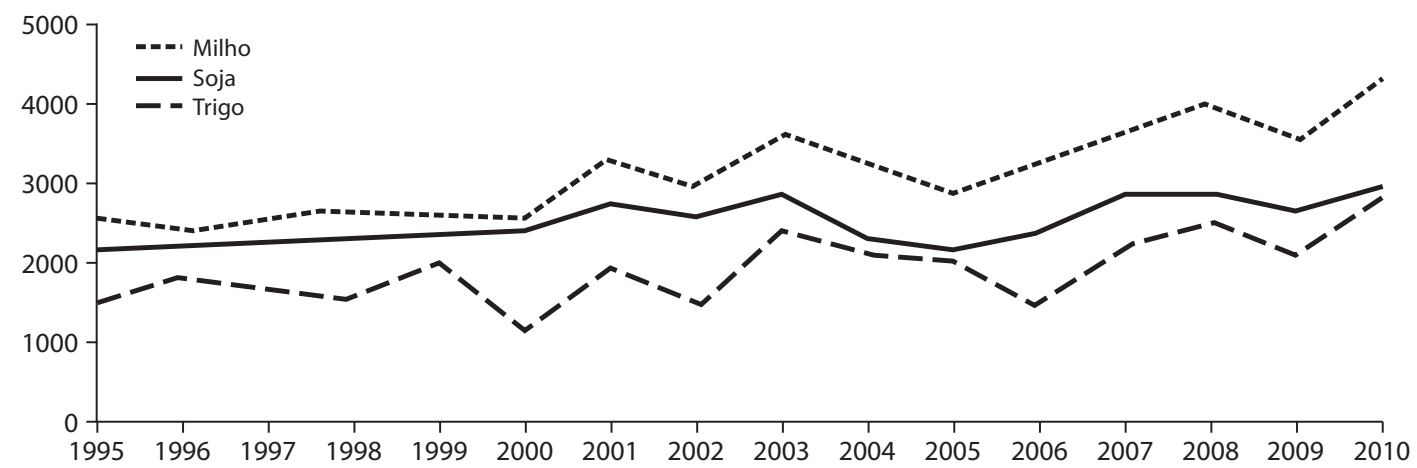

Fonte: Elaborado pelos autores a partir de dados da PAM - IBGE, 2012.

A evolução da produtividade do trigo alcançada pelo Brasil, segundo Tomasini e Ambrosi (1998), reflete esforços de pesquisas, particularmente após a implantação da Embrapa Trigo em 1975, permitindo aos produtores acesso a cultivares mais produtivas e resistentes a doenças, além da disseminação de técnicas de produção mais eficientes.

A Figura 3 retrata os rendimentos das culturas aqui definidas como grupo de verduras e legumes. Os rendimentos da batata-doce e da mandioca, embora tenham permanecido praticamente estáveis no período, apresentaram crescimento de 7,59\% e 7,02\% entre 1995 e 2010 . Para as demais culturas, observa-se tendência de crescimento mais acentuada. Na cultura do tomate, houve elevação de $38,71 \%$ no rendimento, enquanto na batata-inglesa e na cebola detecta-se crescimento mais significativo, 61,69\% e 100\%, respectivamente.

Embora os ganhos de produtividade dessas verduras e legumes sejam notórios, Trento, Sepulcri e Morimoto (2011) destacam alguns problemas do agronegócio brasileiro de verduras, legumes e frutas, em que esses consistem na baixa produtividade e qualidade, alto custo de produção, deficiência na qualificação pós-colheita e altas taxas de desperdício.

A evolução dos rendimentos das culturas do mamão, maçã, banana e laranja pode ser verificada na Figura 4. Observa-se uma tendência acentuada de crescimento da produtividade do

Figura 3. Produtividade das culturas de batata-doce, batata-inglesa, cebola, mandioca e tomate, em kg/ha, Brasil, 1995-2010

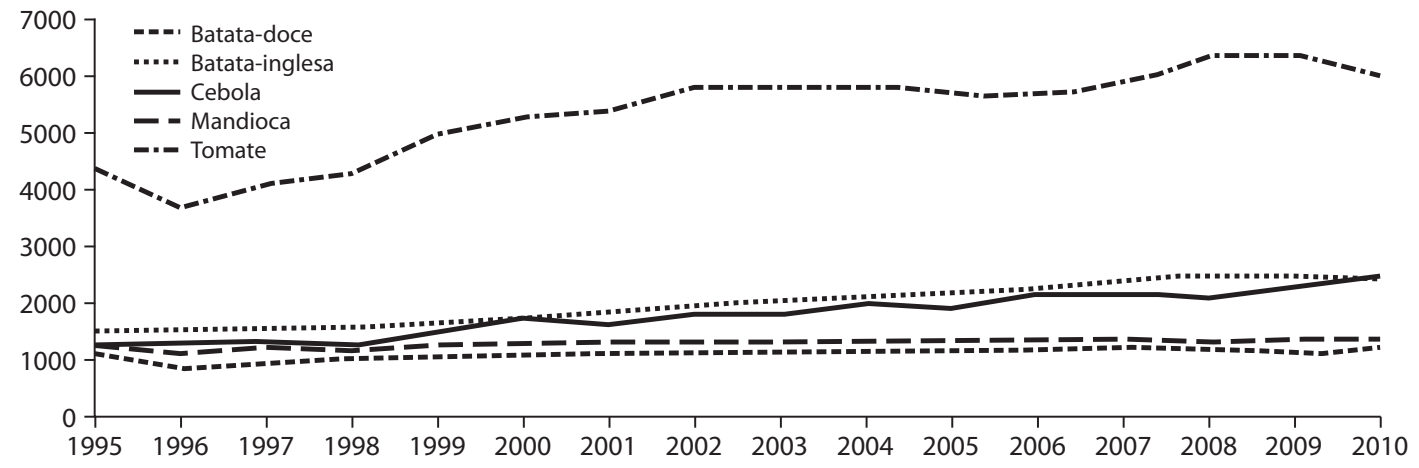

Fonte: Elaborado pelos autores a partir de dados da PAM - IBGE, 2012. 
mamão, com ganho de 50,23\% entre 1995 e 2010. A produtividade da maçã, embora tenha apresentado oscilações, cresceu $29,98 \%$ nesse período. Rendimento crescente também pode ser visualizado na cultura da banana, que, a partir de 2000, mostrou um salto de produtividade, chegando a um crescimento total de $1.209 \%$. Em movimento contrário a todas essas culturas está a produtividade da laranja, que obteve redução de 5,72\%.

As modificações genéticas as quais têm passado a produção do mamão têm possibilitado expressivos ganhos de produtividade no Brasil (BUAINAN e BATALHA, 2007). Conforme destacam os autores referenciados, o cultivo brasileiro de maçã iniciou-se por meio de uma iniciativa governamental com o objetivo de reduzir a dependência externa e contou com o apoio de técnicos americanos e franceses.

Embora o crescimento da produtividade da cultura da banana seja significativo, os produtores brasileiros ainda obtêm baixos rendimentos, que segundo Fioravanço (2003) deve-se ao fato de que a cultura é desenvolvida, em geral, em pequenas propriedades, com emprego de mão de obra familiar, reduzido capital disponível para investimentos e pouca utilização das tecnologias de produção e manejo pós-colheita. Conforme dados da FAO (2012), a Índia, maior produtor mundial dessa fruta, apresentou rendimento médio em 2010 de 37.793,7 kg/ha, contra produtividade média brasileira de 14.329,4 $\mathrm{kg} /$ ha. O salto observado nessa produtividade em 2000 pode estar relacionado ao lançamento de novas cultivares pela Embrapa Mandioca e Fruticultura, desde 1998, mais resistentes à principal doença que afeta a produção: a sigatoka-negra. Além disso, ressalta-se a maior difusão do plantio irrigado, particularmente na região Nordeste do Brasil e norte de Minas Gerais, responsável por elevar a produtividade nessas regiões (EMBRAPA, 2004).

A queda na produtividade da laranja pode refletir em grande disparidade existente entre os rendimentos dos diferentes pomares brasileiros. Segundo Neves e Trombin (2011), a baixa produtividade de parte de seus produtores constitui-se em um dos principais problemas dessa cadeia, comprometendo a lucratividade do setor. Os autores evidenciam que, do total de 317 milhões de caixas de laranjas processadas na safra 2009/2010, $77 \%$ originaram-se de pomares com produtividade média de 909 caixas por hectare, enquanto os $23 \%$ restantes vieram de pomares com produtividade média de 280 caixas por hectare.

De acordo com Buainan e Batalha (2007), as condições favoráveis do clima, solo e disponibilidade de área foram os aspectos que inicialmente permitiram a vantagem brasileira na produção de frutas, que, posteriormente, foi sustentada pelos investimentos em capacitação, logística e inovação tecnológica. Essas ações, associadas ao desempenho positivo do setor no mercado inter-

Figura 4. Produtividade das culturas de banana, laranja, maçã e mamão, em kg/ha, Brasil, 1995-2010.

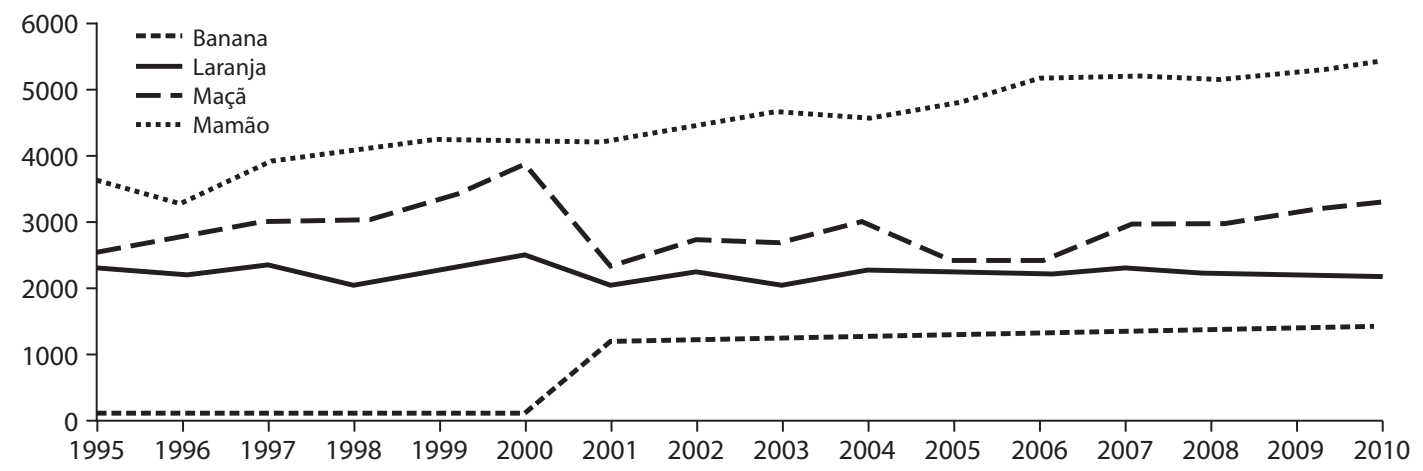

Fonte: Elaborado pelos autores a partir de dados da PAM - IBGE, 2012. 
nacional, possuem importantes implicações sobre os níveis de produtividade.

De modo geral, verificam-se ganhos de produtividade das culturas analisadas, sejam essas mais voltadas ao mercado interno, como o arroz e feijão, ou às exportações, como a soja. Esses resultados são semelhantes aos de Alves (2001), que constata ganhos significativos de produtividade para culturas tanto de exportação quanto de alimentos. Esse fato revela uma modificação em relação ao que foi observado por Mendonça de Barros e Graham (1978), Homem de Melo (1990) e Gonzalez e Costa (1998), autores que verificaram um crescimento de rendimento proporcionalmente maior em direção às culturas exportáveis em detrimento daquelas de mercado interno, particularmente nas décadas de 1970 e 1980.

\subsection{A incidência de insegurança alimentar}

A incidência de insegurança alimentar entre os anos analisados e por estrato de renda per capita pode ser visualizada na Tabela 1.

Em 1995, 27,28\% dos domicílios situados nas regiões metropolitanas brasileiras estavam em situação de insegurança alimentar. Já em 2002, observa-se significativa redução dessa prevalência: 6,95\%. Em 2008, essa proporção foi ainda menor: 5,09\%. Mesmo diante do Plano Real que, segundo Lavinas (1998), possibilitou a estabilização da moeda, elevando a renda real da população, a alta incidência de insegurança encontrada em 1995 pode ser reflexo dos altos índices de inflação ainda persistentes na época, indicando um maior comprometimento da renda da população com a alimentação nesse ano.
Nota-se que, em todos os períodos, o primeiro estrato de renda per capita (abaixo de um salário mínimo) foi o que apresentou maior incidência de insegurança alimentar. Em 1995, $12,21 \%$ dos domicílios pertencentes a esse estrato estavam inseguros; em 2002, 4,69\%; e em 2008, $3,84 \%$. Ressalta-se que, em todas as faixas de renda, houve redução da proporção de domicílios inseguros.

Essa diminuição pode ser resultado dos ganhos de renda da população ao longo dos últimos anos, com repercussões particularmente importantes para os dois últimos biênios analisados. Conforme destacam Barros et al. (2010), entre 2001 e 2007, a renda per capita das famílias brasileiras cresceu, em média, 2,5\% ao ano, sendo que esse crescimento foi de $7 \%$ para os $10 \%$ mais pobres. Ao analisar o período de 2003 a 2007, os autores verificaram uma elevação na renda familiar per capita de 5,4\% ao ano e, para os $10 \%$ mais pobres, uma taxa de crescimento anual de $9 \%$. Esses resultados culminaram na redução dos níveis de pobreza e de extrema pobreza, tendo as transformações na renda não derivada do trabalho (como transferências) relevante contribuição.

No que se refere ao recorte geográfico, a Tabela 2 expõe as proporções de domicílios com insegurança alimentar, por região metropolitana.

Observa-se que, em 1995, Fortaleza apresentou a maior incidência de insegurança alimentar, $41,01 \%$, seguida de perto pela região metropolitana de Belém, $40,45 \%$. Já a menor incidência foi encontrada em São Paulo, 17,84\% de insegurança alimentar.

Em 2002, nota-se uma persistência de maiores incidências de insegurança alimentar entre

Tabela 1. Incidências de insegurança alimentar por estrato de renda, 1995-1996; 2002-2003; 2008-2009

\begin{tabular}{|c|c|c|c|}
\hline \multirow{2}{*}{$\begin{array}{l}\text { Estratos de renda } \\
\text { per capita }\end{array}$} & \multicolumn{3}{|c|}{ Incidência de insegurança alimentar (Gasto excessivo com alimentação) } \\
\hline & $1995-1996$ & $2002-2003$ & 2008-2009 \\
\hline$[0 ; 1]$ & $12,21 \%$ & $4,69 \%$ & $3,84 \%$ \\
\hline$(1 ; 3]$ & $11,88 \%$ & $2,06 \%$ & $1,12 \%$ \\
\hline$(3 ; 5]$ & $2,02 \%$ & $0,14 \%$ & $0,09 \%$ \\
\hline Acima de 5 & $1,16 \%$ & $0,04 \%$ & $0,01 \%$ \\
\hline Total & $27,28 \%$ & $6,95 \%$ & $5,09 \%$ \\
\hline
\end{tabular}

Fonte: Elaboração própria a partir de dados das Pesquisas de Orçamento Familiares, do IBGE. 
Tabela 2. Incidências de insegurança alimentar, por região metropolitana, 1995 a 2009

\begin{tabular}{cccc}
\hline & $\mathbf{1 9 9 5 - 1 9 9 6}$ & $\mathbf{2 0 0 2 - 2 0 0 3}$ & $\mathbf{2 0 0 8 - 2 0 0 9}$ \\
\hline Belém & 40,45 & 10,48 & 9,83 \\
Fortaleza & 41,01 & 12,20 & 8,15 \\
Recife & 34,34 & 9,81 & 5,84 \\
Salvador & 32,20 & 7,96 & 3,40 \\
Belo Horizonte & 19,18 & 3,86 & 3,28 \\
Rio de Janeiro & 20,53 & 6,70 & 3,67 \\
São Paulo & 17,37 & 3,19 & 3,87 \\
Curitiba & 20,49 & 4,97 & 6,39 \\
Porto Alegre & 21,05 & 4,73 & 2,40 \\
Goiânia & 17,84 & 6,56 & 5,12 \\
Brasília & 23,46 & 4,87 & \\
\hline
\end{tabular}

Fonte: Elaboração própria a partir de dados das Pesquisas de Orçamento Familiares, do IBGE.

as regiões metropolitanas do Nordeste e Norte. Embora em níveis muito menores, Fortaleza novamente apresentou a maior proporção: 12,20\%. Em São Paulo, verificou-se que 3,19\% dos domicílios estavam inseguros, o menor nível entre as demais regiões.

Belém e Goiânia foram as regiões de maior e menor incidência de insegurança alimentar em 2008; 9,83\% e 2,40\%, respectivamente. Observa-se, entretanto, uma queda significativa nessas incidências entre 1995 e 2008.

Gubert, Benício e Santos (2010) também encontraram na região Nordeste os maiores níveis de insegurança alimentar grave em 2004, medida pela Escala Brasileira de Insegurança Alimentar (EBIA). Também em 2004, Mondini et al. (2011) verificaram maior incidência de insegurança alimentar nos estados do Nordeste e Norte, enquanto a região Sul mostrou níveis menores. Em 2008, utilizando a Pesquisa de Orçamento Familiar, Costa et al. (2012) também encontraram maiores níveis de insegurança alimentar entre os estados do Nordeste.

\subsection{O efeito da produtividade agrícola sobre a segurança alimentar}

Com o objetivo de verificar e analisar a relação entre produtividade agrícola e segurança alimentar, esta seção apresenta os resultados do modelo probit, que mostra a associação das vari- áveis explicativas à probabilidade de segurança alimentar dos domicílios das regiões metropolitanas brasileiras.

Na Tabela 3 têm-se os valores dos coeficientes estimados e seus valores $p$, que denotam a significância estatística da variável em questão. Além disso, tem-se o efeito marginal (considerando-se os pontos médios) que indica a redução, ou elevação, em pontos percentuais na probabilidade de segurança alimentar, de uma variação unitária em uma variável, mantendo todas as demais constantes. A probabilidade média de segurança alimentar de um domicílio, em todos os anos analisados e em todas as regiões metropolitanas brasileiras, é de $88,67 \%$.

A estatística de Wald mostra que as variáveis utilizadas são conjuntamente significativas, com probabilidade caudal de nulidade conjunta dos parâmetros igual a $0 \%$. Além disso, o modelo apresentou bom ajuste, visto que previu corretamente $85,29 \%$ das observações.

Verifica-se que as variáveis que exercem influência estatisticamente significativa sobre a probabilidade de ocorrência de segurança alimentar nos domicílios brasileiros são: a escolaridade do chefe do domicílio, a presença de pessoas menores de 18 anos, o fato de o domicílio auferir renda per capita inferior a um salário mínimo, residir nas regiões Norte, Centro-Oeste, Sul e Sudeste em detrimento da região Nordeste e as produtividades dos grãos e verduras e legumes. Além disso, 
Tabela 3. Resultados do modelo probit para a segurança alimentar, regiões metropolitanas, 1995 a 2009

\begin{tabular}{|c|c|c|c|}
\hline Variável & Coeficiente & P-valor & Efeito marginal (dy/dx) \\
\hline Escolaridade do chefe do domicílio & $0.008817^{* * *}$ & 0.000 & $0.001692^{* * *}$ \\
\hline Presença de pessoas menores de 18 anos $^{\mathrm{a}}$ & $0.10557^{* * *}$ & 0.000 & $0.20675^{* * *}$ \\
\hline Presença de chefe do domicílio do sexo feminino ${ }^{a}$ & 0.036006 & 0.137 & 0.006849 \\
\hline Domicílios com renda per capita inferior a um salário mínimo & $-1.03052^{* * *}$ & 0.000 & $-0.261202^{* * *}$ \\
\hline Norte $^{\mathrm{a}}$ & $-0.4798^{* * *}$ & 0.000 & $-0.03837 * * *$ \\
\hline Centro-Oeste ${ }^{\mathrm{a}}$ & $0.2971^{* * *}$ & 0.002 & $0.049958^{* * *}$ \\
\hline Sudeste ${ }^{a}$ & $0.07705^{*}$ & 0.066 & $0.065309^{* * *}$ \\
\hline $\mathrm{Sul}^{\mathrm{a}}$ & $0.08853^{*}$ & 0.095 & $0.03672^{* *}$ \\
\hline Produtividade dos grãos & $0.0000986^{* *}$ & 0.016 & $0.0000189^{* *}$ \\
\hline Produtividade de arroz e feijão & -0.0000257 & 0.265 & -0.0000049 \\
\hline Produtividade de verduras e legumes & $-0.0000122^{* *}$ & 0.018 & $-0.0000023^{* *}$ \\
\hline Produtividade de frutas & 0.0000005 & 0.385 & 0.000000103 \\
\hline Produtividade dos grãos em 2002 & -0.000002 & 0.971 & -0.000000408 \\
\hline Produtividade de arroz e feijão em 2002 & 0.0000182 & 0.528 & 0.0000034 \\
\hline Produtividade de verduras e legumes em 2002 & -0.000005 & 0.499 & -0.00000107 \\
\hline Produtividade de frutas em 2002 & $0.000004^{* *}$ & 0.015 & $0.00000091^{* *}$ \\
\hline Produtividade dos grãos em 2008 & $-0.0001778^{* * *}$ & 0.004 & $-0.0000341^{* * *}$ \\
\hline Produtividade de arroz e feijão em 2008 & $-0.0000367^{*}$ & 0.081 & $-0.00000704^{*}$ \\
\hline Produtividade de verduras e legumes em 2008 & $0.0000162^{* *}$ & 0.029 & $0.00000312^{* * *}$ \\
\hline Produtividade de frutas em 2008 & 0.0000009 & 0.620 & 0.000000187 \\
\hline Dummy de $2002^{\mathrm{a}}$ & $0.95962^{* * *}$ & 0.000 & $0.134598^{* * *}$ \\
\hline Dummy de $2008^{a}$ & $1.4570^{* * *}$ & 0.000 & $0.2010073^{* * *}$ \\
\hline Constante & $0.8767^{* * *}$ & 0.000 & \\
\hline Wald $\chi^{2}(22)$ & & 5120.0 & \\
\hline Prob $>\chi^{2}$ & & 0,000 & \\
\hline Classificação Correta & & $85.29 \%$ & \\
\hline Probabilidade de segurança alimentar no ponto médio & & $88,67 \%$ & \\
\hline
\end{tabular}

Nota: a à frente da variável indica que seu efeito marginal refere-se a uma mudança discreta nessa dummy de 0 para 1 . Já os asteriscos à frente dos coeficientes indicam: *estatisticamente significativo a $10 \%$ de probabilidade; **a $5 \%$ e ***a $1 \%$.

Fonte: Resultados da pesquisa.

o diferencial do efeito da produtividade das frutas em 2002, dos grãos, arroz e feijão e verduras e legumes em 2008 também foram significativas.

A significância estatística das variáveis dummies indicativas de tempo mostra que houve de fato uma modificação no intercepto do modelo entre os períodos analisados. Esse fato indica que, controlando todos os demais efeitos observáveis que afetam a segurança alimentar, dados pelas variáveis do modelo, houve elevação na probabilidade de segurança alimentar em $2002 \mathrm{e}$ em 2008, em detrimento de 1995. Essa elevação é resultado de fatores não captados pelas variáveis explicativas do modelo e reflete transformações pelas quais o País passou nesses anos, conforme foi discutido na seção anterior.

Procedendo à análise individual dos efeitos marginais, observa-se que a cada ano adicional na escolaridade do chefe do domicílio tem-se elevação de 0,169 ponto percentual na probabilidade de segurança alimentar. Hoffmann (2008), ao analisar a insegurança alimentar, de acordo com a Ebia em 2004, também encontra relação significativa e positiva entre os maiores níveis de escolaridade da pessoa de referência do domicílio e a probabilidade de segurança alimentar. Essa relação também é encontrada por Mondini et al. (2011), ao comparar as áreas urbanas e rurais em 2004. 
São muitos os caminhos que dão respaldo à relação entre um maior nível educacional e a segurança alimentar. A educação eleva o nível de conhecimento do indivíduo que, segundo Weingärtner (2009), se constitui num dos recursos que os domicílios dispõem para aumentar suas rendas e facilitar o acesso aos alimentos. Além disso, é esperado que maior nível educacional tenha relação direta com cuidados com a saúde e com alimentação, fatores que determinam a segurança nutricional dos indivíduos. Tweeten (1999) ressalta que a utilização do alimento disponível condiciona a segurança alimentar e é resultado do conhecimento e educação nutricional das pessoas. Conforme sugere FAO (2008), além dos investimentos em saúde e saneamento básico, os investimentos em educação também são necessários para auxiliar na redução da insegurança alimentar entre a população.

Outro fator de significativa importância para a elevação da probabilidade de segurança alimentar é a presença de adolescentes e/ou crianças no domicílio. Nota-se que esse fato eleva em 20,67 pontos percentuais a probabilidade de segurança alimentar. Costa et al. (2012) verificaram que a presença de crianças abaixo de seis anos está associada à menor probabilidade de segurança alimentar do domicílio, quando essa é medida com base na aquisição calórica. No entanto, a partir de sete anos, a presença dessas crianças associa-se com uma elevação na probabilidade de segurança alimentar.

A composição dos domicílios, como o número de crianças e adolescentes, está relacionada à utilização dos alimentos disponíveis. A maior probabilidade de segurança alimentar diante da presença de pessoas menores de 18 anos pode sinalizar maior preocupação desses domicílios com alimentação e saúde, elevando a probabilidade de segurança alimentar. A decisão de alocação do alimento disponível entre os indivíduos do domicílio também se constitui em um importante fator que determina a segurança alimentar e nutricional das famílias, sendo que, como ressaltam Berck e Bigman (1993), a distribuição inadequada dos mesmos pode resultar em insegurança.
Quanto à relação entre os rendimentos e a segurança alimentar dos domicílios, observa-se que o fato de o domicílio auferir renda per capita inferior a um salário mínimo reduz a probabilidade de segurança alimentar em 26,12 pontos percentuais em relação aos domicílios em outros estratos de renda per capita. Conforme Hoffmann (2008), a renda per capita domiciliar é o determinante isolado mais importante da insegurança alimentar. Gubert, Benício e Santos (2010) também ressaltam a importância da renda per capita e constatam uma relação inversa entre a mesma e a insegurança alimentar grave em 2004.

O nível de renda se faz importante tanto na capacidade de comprar os alimentos disponíveis quanto na possibilidade de escolha dos domicílios, permitindo-os adquirir alimentos mais saudáveis e de melhor qualidade. Embora a insegurança alimentar tenha dimensões complexas, Maluf (2006) destaca que a pobreza e a vulnerabilidade à fome são fenômenos intrinsecamente relacionados. Fazem parte das recomendações da FAO (2008) para a redução dos níveis de insegurança alimentar as políticas de crescimento e garantia de renda, evidenciando a importância desses fatores para a situação alimentar de um domicílio.

No que se referem aos diferenciais entre as regiões, observa-se que residir na região metropolitana de Belém em detrimento das regiões metropolitanas do Nordeste reduz em 3,83 pontos percentuais a probabilidade de segurança alimentar. Essa mesma probabilidade é elevada em 4,$9 ; 6,53$ e 3,67 pontos percentuais se o domicílio encontra-se em regiões metropolitanas do Centro-Oeste; Sudeste e Sul, respectivamente. Hoffmann (2008) também constata que a região de residência afeta substancialmente a probabilidade de insegurança alimentar no Brasil, em que residir nas regiões Centro-Oeste, Sudeste e Sul reduz a probabilidade de insegurança alimentar em relação à residência na região Nordeste.

As diferenças entre regiões em relação à probabilidade de segurança alimentar podem decorrer de diferenças de renda, de distribuição da mesma, de escolaridade e até mesmo de diferen- 
tes preços das cestas de alimentos consumidos entre as regiões. O Nordeste é a região brasileira com maior incidência de pobreza, mesmo utilizando diferentes concepções da mesma, como em Kageyama e Hoffmann (2006), que consideram, além da renda, o acesso a bens fundamentais como água encanada em pelo menos um cômodo, instalação sanitária no domicílio e iluminação elétrica. Os elementos considerados pelos autores são importantes condicionantes da saúde e da nutrição dos indivíduos, com implicações significativas sobre a segurança alimentar. $\mathrm{O}$ ambiente saudável, incluindo o saneamento básico e o acesso à água potável, é importante instrumento para a segurança alimentar (TWEETEN, 1999).

No que tange às produtividades, os resultados indicam que uma elevação nos rendimentos dos grãos aumenta a probabilidade de segurança alimentar em 1995 em cerca de 0,0018 ponto percentual.

O efeito do crescimento da produtividade dos grãos sobre a segurança alimentar em 1995 pode ser justificado pelo próprio contexto da época. Conforme Farina e Nunes (2002), a queda dos preços agrícolas entre 1994 e 1997 estimulou a queda da inflação, atuando como uma "âncora verde" do Plano Real. Segundo Mendonça de Barros, Rizzieri e Picchetti (2001), a redução de preços observada, embora seja resultado de um conjunto de fatores, decorre essencialmente dos ganhos de produtividade ocorridos no País desde então, sem os quais seria impossível que os produtores continuassem a ofertar seus produtos. Margarido, Martins e Bueno (2006) ressaltam que, em geral, foram os preços dos produtos vegetais que mais contribuíram para a contenção da inflação entre 1995 e 1997, sendo que os produtos animais mostraram um movimento mais acentuado de preços.

Já a elevação da produtividade das verduras e legumes reduz a probabilidade de segurança alimentar (em relação aos gastos) em 1995 em 0,0002 ponto percentual. De acordo com Hazell e Haddad (2001), o aumento de produtividade em um dado item alimentício, com consequente redução de seus preços, pode ser utilizado para elevar o consumo de outros alimentos. Além disso, a elevação da produtividade somente se traduz em menores níveis de preços se o sistema de distribuição é suficientemente competitivo para repassar a redução de custos como redução de preços ao consumidor.

Conforme Trento, Sepulcri e Morimoto (2011) ressaltam, a produção consiste na primeira etapa de um processo maior, o da comercialização, que passa ainda pelo beneficiamento, embalagem, compra, venda e atividades de logística. Particularmente nos casos da produção de verduras e legumes, essa dinâmica implica em uma série de desafios para os produtores, que enfrentam deságios de preços em seus produtos por sua alta perecibilidade, pela colheita às vezes efetuada fora do ponto ideal; pela falta de rastreabilidade e pelo manejo incorreto desses alimentos. Esses fatores afetam a possibilidade de redução nos valores diante de um aumento de produtividade.

Quanto às frutas, verifica-se que uma elevação em seu rendimento está associada a um aumento na probabilidade de segurança alimentar de 0,0001 ponto percentual em 2002. Segundo Silveira et al. (2011), os gastos com frutas se elevam com aumentos da renda domiciliar. Tal fato oferece uma indicação de que o aumento de renda real da população brasileira, entre 1995 e $2002^{8}$, possibilitou maior consumo de frutas. De fato, Buainan e Batalha (2007) observam aumento na demanda doméstica pelas frutas, especialmente mamão, maçã e banana, entre 1996 e 2005. Assim, o aumento da produtividade das frutas, com consequências sobre os preços desses itens, leva à redução nos gastos alimentares em relação à renda, contribuindo para a elevação da segurança alimentar em 2002.

Nota-se que o efeito da produtividade dos grãos sobre a segurança alimentar reduziu-se em 2008 em relação a 1995, culminando numa relação negativa entre esse rendimento e a segurança alimentar. Assim, um aumento na produtividade

\footnotetext{
8 Rocha (2000) ressalta a queda nos níveis de pobreza registrada posteriormente à implantação do Plano Real em 1994.
} 
dos grãos reduz a probabilidade de segurança alimentar em 2008. Também reduzindo a probabilidade de segurança alimentar está a produtividade do arroz e feijão, em que um aumento na mesma está associado a uma redução na probabilidade de segurança alimentar de 0,00001 ponto percentual. Já o efeito da elevação na produtividade das verduras e legumes sobre a segurança alimentar foi maior em 2008 e, nesse caso, positivo, evidenciando que nesse ano há uma elevação na probabilidade de segurança alimentar de um domicílio da ordem de 0,0000008 ponto percentual, com ganho de rendimento nessas culturas.

Cabe ressaltar que 2008 foi marcado por um contexto de crise econômica internacional, com grandes repercussões sobre os preços de alimentos. Além disso, conforme FAO (2009), a crise emergiu imediatamente após um grande aumento que já vinha ocorrendo nos preços de alimentos e combustíveis entre 2006 e 2008. Ao final de 2008, os preços domésticos de alimentos básicos estavam em média $17 \%$ maiores, em termos reais, que em 2006, representando uma redução considerável no poder de compra, particularmente da população de baixa renda. Assim, segundo FAO (2009), o número de pessoas subnutridas no mundo cresceu substancialmente entre 2006 e 2009.

Levando-se em consideração a alta transação dos grãos no mercado internacional, esses produtos tiveram aumento expressivo de preços, fazendo com que os ganhos de produtividade tivessem efeitos contrários, elevando o gasto com alimentação em relação à renda e, por conseguinte, reduzindo a segurança alimentar dos domicílios das regiões metropolitanas brasileiras.

De acordo com Garcia (1979), diante das baixas elasticidades-preço da demanda do arroz e do feijão, uma elevação na oferta desses itens que seja capaz de reduzir seus preços conduz a um aumento na renda real do domicílio, que, por sua vez, é utilizado para o consumo de outros produtos. Uma elevação na produtividade dessas culturas pode estar associada a uma redução dos gastos com esses alimentos, mas em contrapartida a um aumento no consumo de outros produ- tos. Em 2008, diante dos altos preços de alimentos em geral, esse movimento pode ter elevado os gastos alimentares, sendo responsável por reduzir a probabilidade de segurança alimentar.

Embora nem todas as produtividades tenham sido significativas e apresentado os sinais esperados, esses resultados evidenciam que a produtividade agrícola afeta a probabilidade de segurança alimentar dos domicílios brasileiros. Em pelo menos um dos períodos analisados houve influência significativa e positiva dos ganhos de produtividade dos grãos, das frutas e das verduras e legumes sobre a probabilidade de segurança alimentar. Os efeitos marginais relativamente pequenos demonstram o que já era esperado, dado que, conforme ressalta Smith (2002), a disponibilidade interna de alimentos não é condição suficiente para a garantia de acesso dos domicílios aos mesmos, sendo a existência de recursos e de outros fatores importantes determinantes da situação de segurança alimentar. Além disso, os sistemas de comercialização e de processamento de alimentos são importantes segmentos que agregam valor aos produtos agrícolas, reduzindo a possibilidade de repasse dos ganhos de produtividade aos preços pagos pelos consumidores.

\section{Conclusão}

Diante do fato de que uma elevação da produtividade agrícola, em geral, associa-se a menores níveis de preços de alimentos, buscou-se, neste trabalho, verificar a existência de relação entre o crescimento da produtividade agrícola e a segurança alimentar domiciliar no Brasil, entre os biênios 1995-1996, 2002-2003 e 2008-2009.

Os resultados indicam que entre os fatores mais importantes para a explicação da segurança alimentar encontram-se a escolaridade do chefe do domicílio, a presença de pessoas menores de 18 anos e o fato de o domicílio auferir renda per capita inferior a um salário mínimo. No que tange à produtividade agrícola, observou-se que as produtividades dos grãos, das frutas e das verduras e legumes, em pelo menos um dos períodos analisados (grãos em 1995, frutas em 2002 e verduras 
e legumes em 2008) elevaram a probabilidade de segurança alimentar dos domicílios das regióes metropolitanas brasileiras, embora em proporções muito pequenas quando comparadas às demais variáveis analisadas.

Destarte, conclui-se que ainda que a produtividade agrícola seja de fato importante, ela se relaciona infimamente com a segurança alimentar no Brasil. As variáveis socioeconômicas possuem maior poder de relacionamento com o fenômeno em questão e trazem importantes indicações para a política nacional com vistas à segurança alimentar.

Além do crescimento dos programas e políticas sociais com foco na inclusão social e produtiva e na redução da pobreza, tem-se observado, nos últimos anos, avanços na instituição e atuação da política alimentar. Menciona-se a promulgação da Lei Orgânica de Segurança Alimentar e Nutricional (Losan), em 2006; a incorporação do direito humano à alimentação adequada (DHAA) na Constituição em 2010; e o Decreto 7.272 de 2010 com o intuito de assegurar o DHAA, instituindo a Política Nacional de Segurança Alimentar Nutricional (SAN). Entre os objetivos traçados por essa política está a identificação e análise dos fatores que determinam a situação de segurança alimentar no Brasil. Este trabalho contribui para esse item, na medida em que expõe a associação entre variáveis de acesso e disponibilidade de alimentos e a questão alimentar das famílias, possibilitando melhor focalização dos recursos para o alcance das metas acordadas. Cabe destacar que, dentro da Política Nacional de SAN estão traçadas diretrizes, nas quais estão explícitas as metas relacionadas à garantia de renda; abastecimento alimentar; atenção à agricultura familiar e promoção da educação alimentar e nutricional, fatores importantes para a segurança alimentar, conforme mostrado por este estudo.

Ressalta-se, entretanto, que, neste trabalho, a medida de segurança alimentar utilizada enfoca a vulnerabilidade do domicílio, que é determinada pelos seus gastos com alimentação em relação à renda, medida que aborda apenas uma das dimensões desse fenômeno, que é multidimensional. Assim, essa se constitui na principal limitação deste estudo, e sugere-se para pesquisas futuras a consideração das demais dimensões do fenômeno. A utilização de diferentes medidas capta diferentes aspectos da segurança alimentar e pode trazer importantes contribuições para o tema. Além disso, diante da relação entre produtividade agrícola e maior possibilidade de autoconsumo dos produtores rurais, torna-se relevante uma análise da relação entre produtividade e segurança alimentar nessas áreas. Essa análise não pôde ser realizada por esse estudo tendo em vista a abrangência da POF de 19951996, que apenas pesquisou as regiões metropolitanas brasileiras.

\section{Referências bibliográficas}

ALVES, E. Quem ganhou e quem perdeu com a modernização da agricultura. Revista de Economia e Sociologia Rural, Brasília, v. 39, n. 3, p. 9-39, jul./set. 2001.

ALVES, E., CONTINI, E. e HAINZELIN, E. Transformações da agricultura brasileira e pesquisa agropecuária. Cadernos de Ciência \& Tecnologia, Brasília, v. 22, n. 1, p. 37-51, jan./abr. 2005.

BABU, S. C. e SANYAL, P. Food Security, Poverty and Nutrition Policy Analysis: Statistical Methods and Applications. Oxford: Elsevier, 2009.

BARROS, R., CARVALHO, M., FRANCO, S. e MENDONÇA, R. Determinantes da queda na desigualdade de renda no Brasil. Rio de Janeiro: IPEA. Texto para discussão 1460, jan. 2010.

BERCK, P. e BIGMAN, D. The Multiple dimensions of the world food problem. In: BERCK, P. e BIGMAN, D. (Ed.) Food security and food inventories in Development Countries. Wallingford: CAB International, 1993.

BRASIL, Lei no 11.346, de 15 de setembro de 2006. Cria o Sistema Nacional de Segurança Alimentar e Nutricional - SISAN com vistas em assegurar o direito humano à alimentação adequada e dá outras providências. Disponível em: <http://www.planalto. gov.br/ccivil_03/_Ato2004-2006/2006/Lei/L11346.htm>. Acesso em: 20 set. 2011.

BUAINAIN, A. M. e BATALHA, M. O. Cadeia Produtiva de Frutas. 7. Ed. Brasília: IICA: MAPA/SPA, 2007. 
BUAINAIN, A. M. e VIEIRA, P. A. Produtividade na agricultura: o fator esquecido. Disponível em: <http:// www.grupocultivar.com.br/arquivos/Produtividade. pdf>. Acesso em: 14 jul. 2012.

CAMERON, A. C. e TRIVEDI, P. K. Microeconometrics: Methods and applications. New York: Cambridge University Press, 2005. 1034 p.

CARVAlHO, M. A. e SILVA, C. R. L. Mudanças no Consumo de Alimentos da População Pobre Paulista. Disponível em: < http://www.iea.sp.gov.br/out/LerTexto. php?codTexto $=11994>$. Acesso em: 25 out. 2011 .

CONTINI, E., GASQUES, J. G., ALVEZ, E. e BASTOS, E. T. Dinamismo da agricultura brasileira. Revista de Política Agrícola, Brasília, jul. 2010. Edição Especial.

COSTA, L. V., SILVA, M. M. C., BRAGA, M. J. e LIRIO, V. S. Fatores associados à segurança alimentar nos domicílios brasileiros em 2009. In: CONGRESSO DA SOCIEDADE BRASILEIRA DE ECONOMIA, 50., 2012, Vitória. Anais... Brasília, DF: SOBER, 2012.

ECONOMIST INTELLIGENCE UNIT. Global Food Security Index. Disponível em: <http:// foodsecurityindex.eiu.com/> . Acesso em: 20 jul. 2012.

EMPRESA BRASILEIRA DE PESQUISA AGROPECUÁRIA - EMBRAPA. Novas variedades de banana resistem à Sigatoka Negra, 2004. Disponível em: <http:/www.embrapa.br/imprensa/noticias/1999/ dezembro/bn.2004-11-25.3875291777/>. Acesso em: 07 jul. 2012.

FAN, S., HAZELL, P. e THORAT, S. Linkages Between Government Spending, Growth, and Poverty in Rural India. Research Report 110. International Food Policy Research Institute. Washington, D.C., 1999.

FARINA, E. M. M. Q. e NUNES, R. A evolução do sistema agroalimentar e a redução de preços para o consumidor: o efeito de atuação dos grandes compradores. São Paulo: Oficina PENSA, Estudo Temático 02, 2002.

FIOVARANÇO, J. C. Mercado mundial da banana: produção, comércio e participação brasileira. Informações Econômicas, São Paulo, v. 33, n. 10, out. 2003.

FOOD AND AGRICULTURE ORGANIZATION OF THE UNITED NATIONS-FAO. An introduction to the basic concepts of food security, 2008. Disponivel em: <http://www.fao.org/docrep/013/a1936e/a1936e00. pdf> . Acesso em: 12 dez. 2011.

. How to feed the world in 2050, 2009. Disponivel em: <http://www.fao.org/fileadmin/templates/wsfs/ docs/expert_paper/How_to_Feed_the_World_in_2050. pdf $>$. Acesso em: 20 jan. $20 \overline{12}$.
. Estatísticas, 2012. Disponível em: <http:// faostat.fao.org/site/339/default.aspx>. Acesso em: 15 jan. 2012.

GARCIA, J. C. Influência do aumento na oferta de alimentos sobre a nutrição humana. Brasília: Binagri, 1979. 150 p.

GASQUES, J. G., BASTOS, E. T., BACCHI, M. R. P. e VALDES, C. Produtividade da agricultura brasileira. In: MATTOS, L. B. de, TEIXEIRA, E. C. e FONTES, R. M. O. (Ed.). Políticas Públicas e Desenvolvimento. Viçosa: Suprema, 2011. p. 263-276.

GUBERT, M. B., BENÍCIO, M. H. D. e SANTOS, L. M. P. dos. Estimativas de insegurança alimentar grave nos municípios Brasileiros. Caderno Saúde Pública, Rio de Janeiro, v. 26, n. 8, 2010.

HAZELL, P. e HADDAD, L. Agricultural Research and Poverty Reduction. Food, Agriculture, and the Environment Discussion Paper n. 34 International Food Policy Research Institute. Washington, D.C., 2001.

HELFAND, S. M. e PEREIRA, V. de F. Determinantes da Pobreza Rural e Implicações para a Política Pública no Brasil, 2011. Disponível em: <http://www.iica.int/Esp/ regiones/sur/brasil/Lists/DocumentosTecnicosAbertos/ Attachments/394/Texto \% 20Steven \% 20Helfand \% 20 -\%20Final \%20-PT\%20126\%20NEAD.pdf >. Acesso em: 02 fev. 2012.

HOFFMANN, R. Determinantes da Insegurança Alimentar no Brasil: Análise dos Dados da Pnad de 2004. Segurança Alimentar e Nutricional, Campinas, v. 15, n. 1, p. 49-61, 2008.

HOMEM DE MELLO, F. O crescimento agrícola brasileiro dos anos 80 e as perspectivas para os anos 90 . Revista de Economia Politica, São Paulo, v. 10, n. 3, jul./ set. 1990.

INSTITUTO BRASILEIRO DE GEOGRAFIA E ESTATÍSTICA - IBGE. Estatísticas. Disponível em: < http://www.ibge.gov.br/>. Acesso em: 05 fev. 2012. 2006. 140 p.

PNAD Segurança alimentar 2004. Rio de Janeiro:

. PNAD Segurança Alimentar 2004/2009. Rio de Janeiro: 2010. 183 p.

Agricultura familiar ocupava $84,4 \%$ dos estabelecimentos agropecuários. Disponível em: <http:// www.ibge.gov.br/home/presidencia/noticias/noticia visualiza.php?id_noticia $=1466 \& i d$ _pagina $=1>$. Acesso em: 18 dez. 2011.

- Microdados da POF 2008-2009 (Pesquisa de Orçamentos Familiares). Disponível em: <http:// 
www.ibge.gov.br/home/estatistica/populacao/ condicaodevida/pof/2008_2009/microdados.shtm >. Acesso em: 20 abr. 2011.

KAGEYAMA, A. e HOFFMANN, R. Pobreza no Brasil: uma perspectiva multidimensional. Economia e Sociedade, Campinas, v. 15, n. 1, p. 79-112, jan./jun. 2006.

KEPPLE, A. W. e SEGALL-CORRÊA, A. M. Conceituando e medindo segurança alimentar e nutricional. Ciência e Saúde Coletiva, Rio de Janeiro, v. 16, n. 1, p. 187-199, 2011.

LAVINAS, L. Acessibilidade alimentar e estabilização econômica no Brasil nos anos 90. Rio de Janeiro: IPEA, Texto para discussão 591,1998.

MALUF, R. S. Segurança Alimentar e Fome no Brasil: 10 anos da Cúpula Mundial de Alimentação. CERESAN, Relatórios Técnicos, n. 2, 2006.

. e MENEZES, F. Caderno "Segurança Alimentar", 2000. Disponível em: < http://www.forumsocialmundial. org.br/download/tconferencias_Maluf_Menezes_2000_ por.pdf>. Acesso em: 14 out. 2011.

MARGARIDO, M. A., MARTINS, V. A. e BUENO, C. R. F. Análise da evolução de índices de preços pós Plano Real: Digressões sobre a propalada "âncora verde". Informações Econômicas, São Paulo, v. 36, n. 8, p. 39-55, ago. 2006.

MENDONÇA DE BARROS, J. R. e GRAHAM, D. H. A Agricultura brasileira e o problema da produção de alimentos. Pesquisa e Planejamento Econômico, v. 3, n. 8, 1978.

., RIZZIERI, J. A. B. e PICCHETTI, P. Os efeitos da pesquisa agrícola para o consumidor. Fundação Instituto de Pesquisas Econômicas, Relatório de Pesquisa, São Paulo, 2001.

MINTEN, B. e BARRET, C. B. Agricultural Technology, Productivity, Poverty and Food Security in Madagascar. Disponível em: <http://dyson.cornell.edu/special_ programs/AFSNRM/Parima/Papers\%20from $\% 20 \mathrm{Cbb} 2 /$ Papers/MB_agriculture.pdf > . Acesso em: 10 out. 2011.

MOFFITT, R. Identification and estimation of dynamic models with a time series of repeated cross-sections. Journal of Econometrics, v. 59, p. 99-123, 1993.

MONDINI, L., ROSA, T. E., GUBERT; M. B., SATO, G. S. e BENICIO, M. H. A. Insegurança alimentar e fatores sociodemográficos associados nas áreas urbana e rural do Brasil. Informações Econômicas, São Paulo, v. 41, n. 2, p. 52-60, fev. 2011.

NEVES, M. F. e TROMBIN, V. G. Análise de uma década na cadeia da laranja, 2011. Disponível em: < http:// www.favaneves.org/arquivos/analise-de-uma-decadalaranja.pdf>. Acesso em: 18 jun. 2012.

PINSTRUP-ANDERSEN, P. e HAZELL, P. B. R. The Impact of the Green Revolution and Prospects for the Future. Food Reviews International, v. 1, n. 1, p. 1-25, 1985.

RAFFERY, A. e WALTHERY, P. Analysing change over time: a guide to ESDS microdata resources, 2011. Disponível em: <http://www.esds.ac.uk/government/ docs/analysingchange.pdf $>$. Acesso em: 06 abr. 2012.

ROCHA, S. Pobreza e desigualdade no Brasil: o esgotamento dos efeitos distributivos do Plano Real, 2000. Disponível em: <http://www.ipea.gov.br/pub/td/ td_2000/td0721.pdf $>$. Acesso em: 20 maio 2012.

SCHLESINGER, S. Soja: o grão que segue crescendo. Grupo de Trabalho sobre Desenvolvimento e Meio Ambiente nas Américas, Documento de Discussão 21, jul. 2008.

SEN, A. Desenvolvimento como liberdade. Tradução Laura Teixeira Motta. São Paulo: Companhia das Letras, 2010. $459 \mathrm{p}$.

SILVEIRA, J., GALESKAS, H., TAPETTI, R. e LOURENCINI, I. Quem é o consumidor brasileiro de frutas e hortaliças? Hortifruti Brasil, p. 8-23, jul. 2011.

SMITH, L. C. The Use of Household Expenditure Surveys for the Assessment of Food Insecurity. In: Organização das Nações Unidas para Agricultura e Alimentação - FAO. Measurement and Assessment of Food Deprivation and Undernutrition. Roma: 2002. 55 p.

SOUTHGATE, D. D., GRAHAM, D. H. e TWEETEN, L. G. The world food economy. 2. ed. Hoboken: Wiley, 2011.

TOMASINI, R. G. A. e AMBROSI, I. Aspectos econômicos da cultura de trigo. Cadernos de Ciência $\mathcal{E}$ Tecnologia, Brasília, v. 15, n. 2, p. 59-84, maio/ago. 1998.

TRENTO, E. J., SEPULCRI, O. e MORIMOTO, F. Comercialização de frutas, legumes e verduras. Curitiba: EMATER, Série Informação Técnica 085, 2011.

TWEETEN, L. The Economics of Global Food Security. Review of Agricultural Economics, v. 21, n. 2, p. 473-488, 1999.

WEINGÄRTNER, L. The concept of food and nutrition security. In: KLENNERT, K. (Ed.) Achieving Food and Nutrition Security. 3. ed. Feldafing: InWent, 2009, p. 21-52.

WOOLDRIDGE, J. M. Econometric analysis of cross section and panel data. Cambridge: The MIT Press, 2002. $752 \mathrm{p}$.

WOOLDRIDGE, J. M. Introdução à Econometria: uma abordagem moderna. Tradução José Antônio Ferreira. 4. ed. São Paulo: Cengage Learning, 2010. 701 p. 
Anexo 1. Quantidade produzida de arroz e feijão, em toneladas, Brasil, 1995-2010

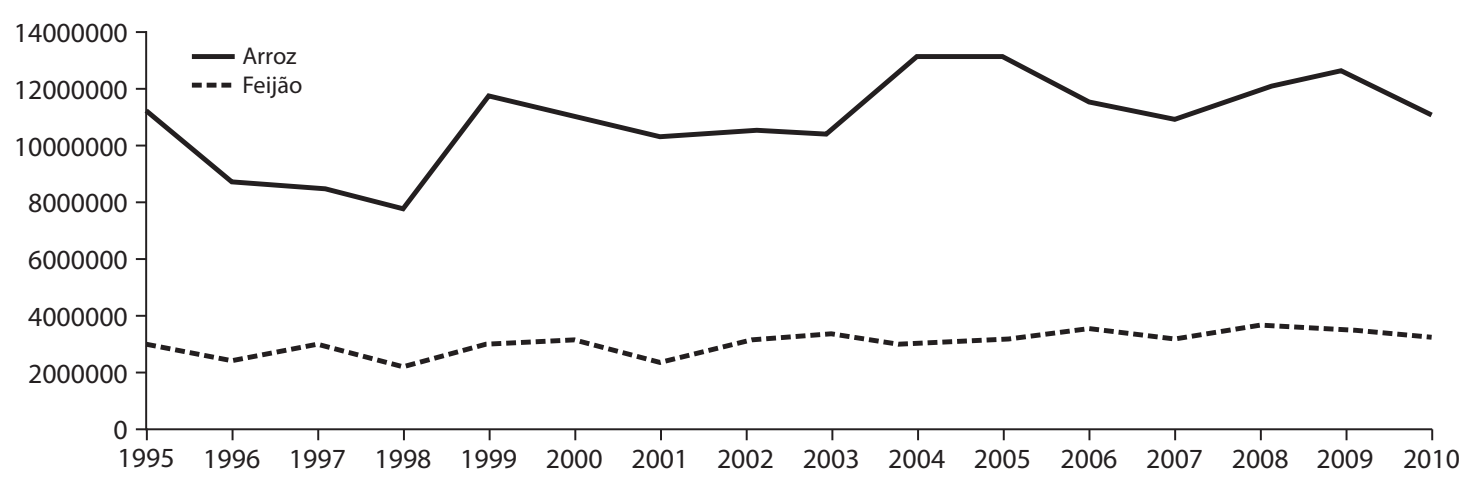

Fonte: Elaborado pelos autores a partir de dados da PAM - IBGE, 2012.

Anexo 2. Quantidade produzida de milho, soja e trigo, toneladas, Brasil, 1995-2010

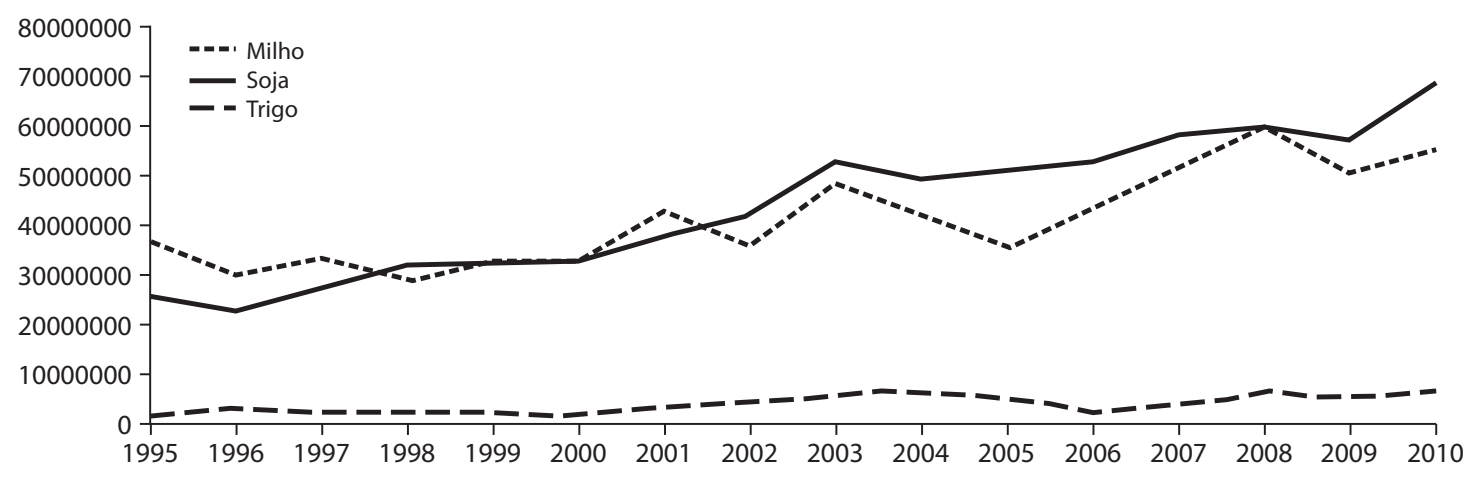

Fonte: Elaborado pelos autores a partir de dados da PAM - IBGE, 2012.

Anexo 3. Quantidade produzida de verduras e legumes, em toneladas, Brasil, 1995-2010

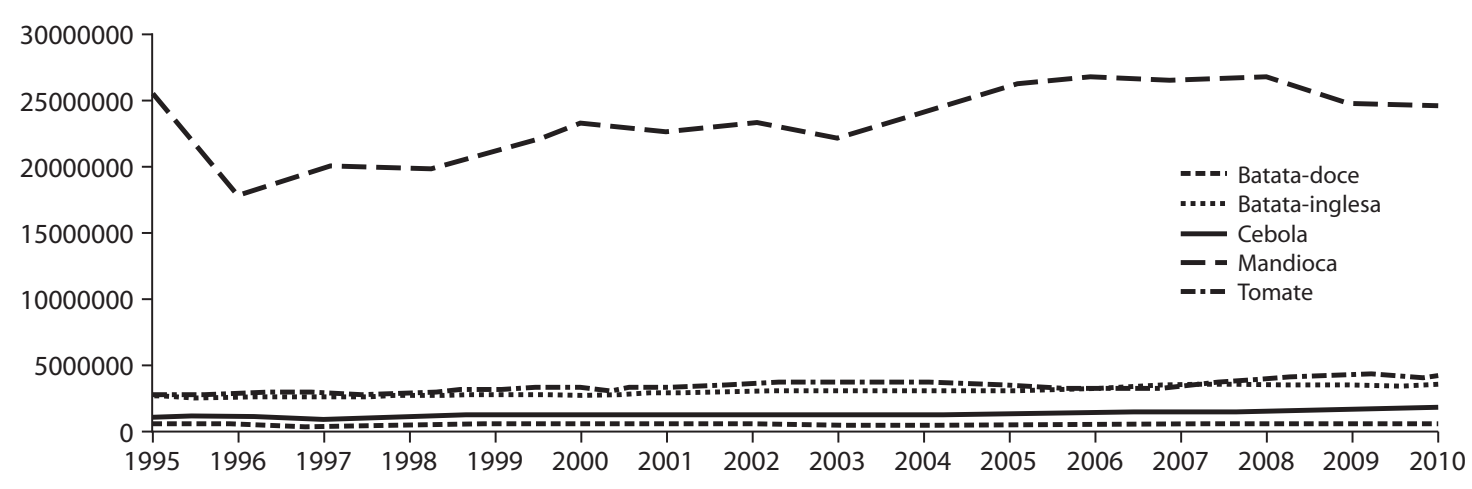

Fonte: Elaborado pelos autores a partir de dados da PAM - IBGE, 2012. 
Anexo 4. Quantidade produzida de banana, laranja, maçã e mamão, em toneladas, Brasil, 1995-2010

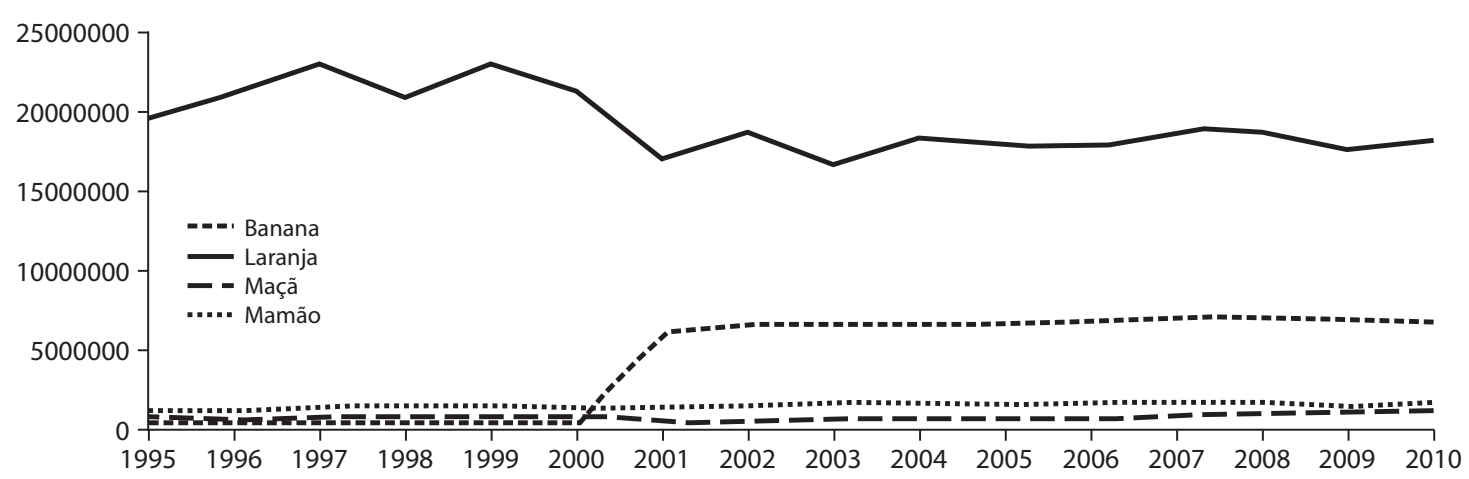

Fonte: Elaborado pelos autores a partir de dados da PAM - IBGE, 2012. 